Zhou Jia

National Art Museum of China

\title{
THE STUDY OF YANGLIUQING NEW YEAR PICTURE
}

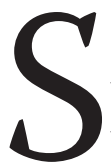

ounds of firecrackers beckon the first day of a new year, as the spring breeze warms the medicinal wine. Thousands of households under the brilliance of a morning sun, replacing wooden door charms of yesteryear." Wang Anshi's poem "Yuan Ri" depicts an uplifting scene of joy and activity, as well as the refreshed atmosphere during Chinese Lunar New Year. Since ancient times, people have been practicing the custom of replacing old with new, by attaching various New Year pictures such as "Door Gods" to refresh the outlook of one's entrance as a sign of good blessings and fortune. The initial stage of this artistic form might date back to the 3rd century B.C. when there was a record of warriors drawn on peach boards. In the 10th century (the Song Dynasty), with the development of the engraving typography, the New Year picture became an independent category and presented colourful prints (fig. 1). The period from the 14th century to the early 20th century (the Ming and Qing Dynasty) were the heyday of New Year pictures. Their workshops were spread all over the country, comprising those such as Yangliuqing of Tianjin, Taohuawu in Jiangsu Province, Wuqiang in Hebei Province, Yangjiapu in Shandong province and Fengxiang in Shaanxi province. Among them, Yangliuqing's New Year pictures are highly reputed as the "pinnacle of quality" within the art of New Year painting, renowned for their exquisite engravings, delicate colourings, rich diversity of styles as well as huge influence. 


\section{HISTORY AND DEVELOPMENT}

Located in Tianjin, China, the town of Yangliuqing is widely known for its lush willows. Yangliuqing was a transportation and business hub; a city bustling with countless shops and blessed with gorgeous picturesque scenery, it was known as the "Small Suzhou and Hangzhou" of Northern China. In such a thriving and conducive environment, there is no exact record of the beginning period that New Year picture production appeared in Yangliuqing. According to the research of scholars specializing in the study of New Year pictures such as Wang Shucun, Zhang Yingxue, and A Ying, the Yangliuqing New Year picture appeared around the reign of Emperor Wanli (1573-1620) in the Ming Dynasty. Among them, Mr Wang Shucun's inference is the most detailed. Based on historical literature and the oral accounts given by painters active somewhere between the reigns of Emperor Tongzhi (1862-1874) and Emperor Daoguang (1821-1850) in the Qing Dynasty, Mr Wang Shucun provided a detailed elaboration in his book: "According to the opening date of the old painting workshop Dai Lianzeng(戴廉增) and the Dai’s family tree, Yangliuqing New Year picture starting from Wanli period is reasonable"1). Few New Year pictures in the Ming Dynasty are extant today (fig. 2). Mr Wang Shucun had four important examples in his collection - Door Gods, Auspiciousness, Peace all year round and Prosperity. "Colored on silk, all four Ming masterpieces bear the typical features of exquisite engravings and delicate colorings which evidently a collaboration of court artists." ${ }^{2)}$ These suggest that Yangliuqing New Year pictures had already been used as tributes to the court in the late Ming Dynasty.

It was slowly developed and refined until the early period of the Qing Dynasty. It then eventually peaked in the mid to late period of the Qing Dynasty, with Yangliuqing as the main hub and over 3,000 artists spread across all 36 villages north of town; this was the grand occasion of a golden era. "All families can colour, every household is skilled in painting." This local saying fully depicts the thriving and booming industry of New Year pictures in Yangliuqing.

After the Daoguang Period (1821-1850) of the Qing Dynasty following the Prosperous Era of Emperors Kangxi and Qianlong, changes took place in both the form and content of Yangliuqing New Year pictures. A large number of

\footnotetext{
1) Wang Shucun (1959: 2-3).

2) Wang Shucun (2001:17).
} 
New Year pictures realistically portraying modern life emerged in this historical period. In the last years of the Qing Dynasty and throughout the Republic of China (1911-1949), traditional woodblock and hand-painted New Year pictures were influenced by inexpensive foreign papers and pigments as well as the development of lithography and offset printing technology in Tianjin. Moreover, after the Lugouqiao Incident in 1937, the Japanese aggressors forcibly plundered countless precious New Year woodblocks in Yangliuqing. Most of the workshops shut their doors. Only less than 17 workshops still struggled to survive, such as Wanshengheng, Wantaichang, Yishunhao and Rongchanghao etc.

After the founding of the People's Republic of China, the endangered Yangliuqing New Year pictures resumed production with the support of the government. In 1953, several senior artisans in Yangliuqing spontaneously organized and established the New Year Picture Producer's Mutual-Aid Team, later renamed Yangliuqing New Year Picture Producer's cooperative. Many famous experienced artisans, like Zhang Xingze (1886-1963) and Pan Zhongyi (1902-1984), took apprentices to teach their skills. It shows that the production capabilities of Yangliuqing New Year pictures had not been lost and maintained their high level. In 2006, the artisanal techniques of Yangliuqing New Year pictures were included in the first batch of China's intangible cultural heritage.

Thanks to the widespread influence of Yangliuqing New Year pictures, since the late Qing Dynasty, some foreign scholars and missionaries started collecting them (fig 3). Now Russia and Japan have the largest collection of Yangliuqing paintings. The first Chinese institutions to collect folk New Year paintings were the Peking University Society of Chinese Customs and Centre Franco-chinois d'etudes Sinologiques. Individuals such as Lu Xun, Zheng Zhenduo, A Ying, Lou Zikuang and Wang Shucun also collected them. To single out Yangliuqing paintings, Mr Wang Shucun had the most comprehensive and systemic collection of the best of these paintings. From the 1960s until 2012, Mr. Wang Shucun and his family donated his collection of Yangliuqing New Year pictures to the National Art Museum of China (NAMOC) four times. These works have laid a good foundation for the NAMOC's New Year picture collection system. 


\section{THEME}

Passed down from ancient to modern times, the themes shown by New Year pictures from Yangliuqing include historical classics and opera narratives, secular scenes with male farmers and female seamstresses, as well as images with a multitude of elements symbolizing the auspicious and festive New Year atmosphere (fig. 4). These various themes all offer connotations of positivity that fulfill the people's needs and wants. Over the centuries, these pictures have remained a custom that is beloved and enjoyed by people during every New Year season. In general, the Yangliuqing New Year picture can be divided into five categories according to their theme: characters, scenery, folks, historical stories and gods. Each category includes hundreds of kinds of works, totalling no less than two thousand. They are like an encyclopedia that reflects folk life, rich in content, positive, optimistic and full of fun.

The origins of New Year folk paintings began from the "Door Gods" (fig. 5). From the very first iconography of worship such as tigers or wooden charms displayed at one's entrance, to the various common paintings of Gate Gods after the invention of woodblock printing, the image of Door Gods has always been modified and passed down through the generations. Early versions included Shenshu and Yulü, Dushuo Mountain's ghost-capturing brothers from the Chinese classic "Shan Hai fing", "God's fudgment: Zhong Kui" by Wu Daozi of the Tang Dynasty, civil and martial Door Gods of the Song Dynasty, as well as the secular imagery of Door Gods from the Ming and Qing Dynasties, mostly represented by heroes of popular novels. The most renowned Door Gods were the famous generals Qin Qiong and Yuchi Gong of the Sui and Tang dynasties, when images of ladies and children were integrated into various types of door pictures. Gradually, the purpose of Door Gods changed from seeking the divine protection of invincible beings to decorating and beautifying one's entrance. Simultaneously, new themes began emerging in these New Year pictures.

Yangliuqing's pictures of Door Gods can be roughly divided into three types: a mace-wielding, arrow-equipped military general Door God cloaked in armour, a charitable civil Door God wearing a Chinese official's costume, and a door child with auspicious symbolic objects. In addition, due to its proximity to the capital, the Door God pictures on the palace gates of the Forbidden City were all from Yangliuqing. It was also known that a large gilded picture of the Door Gods with clouds billowing against a green background was customized for the palace and its residence (fig. 6). 
Most New Year pictures from Yangliuqing are based on historical stories, folk legends and famous novels that include teachings of loyalty and filial piety, the importance of virtue, righteousness and wisdom as well the scholar-beauty genre, depicting the most exciting and engaging chapters with strong narrative and educational value. In the early Qing Dynasty, this style of painting inherited the traditions of draftsmanship, emphasizing the characters' expressions with a solemn atmosphere until the middle period of the Qing Dynasty, when the style of approach gradually shifted emphasis to portraying scenes of prosperity and activity, along with a soft and delicate colour palette.

With the prosperous development of opera culture in the Qing Dynasty, a style of New Year painting emerged with an opera repertoire as its theme (fig. 7). Performances within an opera repertoire were called "chu"(出), hence the title “Xi Chu Nian Hua" (戏出年画) or "Plays of the New Year Pictures". People loved these depictions as they were able to enjoy and relive wonderful opera scenes without leaving their homes (figs. 8. 9). The paintings can be divided formally into two categories; during the early period, realistic portrayals of mountains and rivers, horses and carriages are juxtaposed with the staged expressions and behavioural postures of characters, while a more direct and formal approach was used in a later period to represent elements of a staged opera's performance sequence, such as a horse whip to represent horse riding, oars to represent a boat, a flag to represent a royal carriage.

During the Revolution of 1911, many workshops like Qi fianlong and Dai Lianzeng created a new theme named “Western Scenery”(西洋镜) under the influence of a new trend of thought, catering to the people's progressive thinking (fig. 10). This genre of New year pictures depicts images of Western diorama and are used for acting and singing performances. The contents are mostly scenic, sometimes with topics of politics, narratives and more.

\section{PRODUCTION METHOD}

In a nutshell, the process of producing a Yangliuqing New Year picture includes four main steps: outlining, engraving, printing and painting, hence resulting in craftsmanship that portrays the tonal contrast between the bold and intricate. High-in-demand pictures such as deities are boldly coloured via woodblock printing or large brush painting (fig. 11). Intricate paintings with the themes of narratives or operas are applied with delicate colours 
and even gold powder. Mountains, trees, clothing and facial features such as eyebrows are printed with finer ink outlines or colours (yellow, green, grey) before being hand-smudged. The unique semi-printed and semi-painted craftsmanship of Yangliuqing New Year pictures both maintains the exquisite, lustrous charm of woodblock printing and preserves the style of traditional folk painting.

In the past, a half-printed and half-painted woodcut New Year picture was the result of the collective creation of many artists and craftsmen. It had to be completed by the sketch designer, engraver, brush worker and painter. Each process has its own requirements. Sketching is the most crucial step in a Yangliuqing New Year picture (fig. 12). It is directly related to the quality and sales of the New Year painting. Sketching has always been performed by the experienced painters who need to deal with the sales of these New Year pictures as well as the feasibility of subsequent steps after printing (fig. 13). In order to make the large number of prints without losing the original painting effect, the technical requirements for the engraving are also very strict. The lines are required to be smooth, precise and concise. The thickness and rigidity of the lines also change with the different contents and the characters. Along with woodblock colour printing as a basis, the works are also required to be hand-painted (fig. 14). Painting for New Year pictures in Yangliuqing was always completed by women, who are thought to be more patient and meticulous.

Through a long period of practice, local folk artists have also formed a set of techniques and formulas to be used as instructions for the creative process of New Year pictures; the traces of these guidelines can be found in the thousands of Yangliuqing New Year picture manuscripts that were handed down. For example, the pithy formula of portrait a child is as followed: "Short arms short legs and a big head, small nose and big eyes with no neck; nose and eyebrows close together, be careful not to show the bones." (fig. 15).

\section{MATERIALS AND TOOLS}

The production materials of Yangliuqing New Year picture are unique. The plates were made of a special tree that is abundant in the town - Pyrus betulaefolia wood. This wood is an excellent engraving material due to the hard, fine texture as well as the quality of resistance to the wear and tear caused by repeated printing. Nowadays, this kind of wood is hard to find in 
Yangliuqing. Thus, the inheritors are always cautious in their carving to avoid material waste. The wood should be sawn according to the size of the picture. The thickness is about $20 \mathrm{~cm}$. The plates should be levelled and polished with sandpaper. The fist knife and the bevel cutter are the main engraving tools, sharpened keenly on two sides. Auxiliary tools include a bending chisel, flat chisel, chisel stand, triangular knife and circular knife etc.

In terms of paper selection, in the Ming and Qing Dynasties, various types of rice paper were chosen according to the fineness of the New Year pictures, from high-end to low-priced. In the late Qing Dynasty, most of the workshops used Japanese imitation writing paper for profit. After the founding of the People's Republic of China, rice paper was retuned to use. Rice paper cannot be used directly for printing. An appropriate amount of alum should be added to the rice paper to ensure a colour that is clear and transparent.

Coloured pigments play an important role in determining whether New Year pictures will fade or not. Before the Daoguang Period (1821-1850) of the Qing Dynasty, most of the pigments were purchased directly from Suzhou and Hangzhou (fig. 16). However, some special pigments were still made using ancient techniques. Take yellow as an example, the fabrication method of the yellow pigment involves stir-frying stemmed dry locust tree flowers with an appropriate amount of lime, adding fried alum and stirring the yellow juice with a stick. As for black, it made by combining bottom ash and oxhide gelatin. From the Daoguang Period of the Qing Dynasty, workshops began to use imported chemical colours which made the New Year pictures fade easily. After the founding of the People's Republic of China, workshops reverted to using traditional Chinese painting pigments.

\section{ARTISTIC STYLE}

The shaping of the Yangliuqing New Year picture artistic style is closely related to its geographical location and environmental factors. Yangliuqing is adjacent to the capital city. From the Ming and Qing Dynasties, this was a township was a prosperous business hub, both affluent and populous. The themes and colours of Yangliuqing New Year pictures were under the dual influence of the civic culture and court art which had turned out to be quite unique with different origins of New Year pictures. In the Qing Dynasty, many famous court painters, such as Qian Hui'an, Zhang Zhusan and Gao Yinzhang, participated in the creation of Yangliuqing New Year 
pictures. They incorporated the ornate and delicate painting style of the court, and even the royal architecture and garden landscape into the Yangliuqing New Year pictures (fig. 17). Qian Hui' an(1833-1911) was a resident of Baoshan in the Jiangsu province. Since a young age, he had developed an interest in painting and was skilled in portraying figures, flowers as well as landscapes. He was invited to travel to the north where he successively produced new samples and handed down outlined drafts as well as paintings for New Year picture workshops such as Qijianlong and Aizhuzhai of Yangliuqing. Qian Huian incorporated the styles of the literati and courtyard paintings into the New Year pictures of Yangliuqing, with themes based mostly on literary quotes and poem verses of predecessors. His paintings are preeminent, refined and elegant. The oval faces and slender figures of females appearing in Yangliuqing New Year pictures, and the special lines such as the bowstring, are all influenced by Qian Hui'an.

The colours used in Yangliuqing New Year pictures is elegant and sprightly. The chromaticities of adjacent colours are differentiated. For example, if a character's blouse were painted in red, white ought to be added to the blue when painting the skirt (fig. 18). Painting in muddy and dark colours are a great taboo in Yangliuqing New Year pictures. This is connected with an old burial custom. In 1799, Emperor Qianlong passed away. Hence, Emperor Jiaqing promulgated the imperial edict that during the period of state mourning, gongs and drums, as well as red and purple colours were not allowed to be used under any circumstances. Therefore, artisans in Yangliuqing created a special type of New Year picture - "three Blue Ink", a New Year picture which is made with three types of blue and three types of ink. Moreover, since then, this kind of New Year picture was only pasted in the family with funeral.

\section{CONCLUSION}

Yangliuqing New Year pictures - visible in various forms of age-old customs at Chinese spring festivals, ebullient with pure joy and emotion, filled with bold imagination and creativity - constitute a significant element of Chinese cultural heritage. It is deeply rooted in the past, and despite civilizational transformations, is still present in the contemporary culture. Regional and local organizations ought to make efforts to preserve and further promote it. Undoubtedly, such actions require stronger support. 


\section{BIBLIOGRAPHY}

Wang (1959) = Wang Shucun, The Sourcebook of Yangliuqing New Year Picture, People's Fine Arts Publishing House, 1959 (1st ed.).

Wang (2001) = Wang Shucun, Yangliuqing New Year Picture, ECHO of Things Chinese, 2001:17.

Wang (2002) = Wang Shucun, The History of Yangliuqing New Year Picture, Beijing Industrial Art Publishing house, 2002 (1st ed.).

A Ying (1954) = A Ying, The Brief History of Chinese New Year Picture, Zhaohua Fine Arts Publishing House, 1954 (1st ed.).

Bo Songnian (2008) = Bo Songnian The History of Chinese New Year Picture, Hunan Fine Arts Publishing House, 2008 (1st ed.).

Zhang (1957) = Zhang Yingxue, Selections of Yangliuqing New Year Picture, Chinese Classical Art Publishing House, 1957 (1st ed.). 


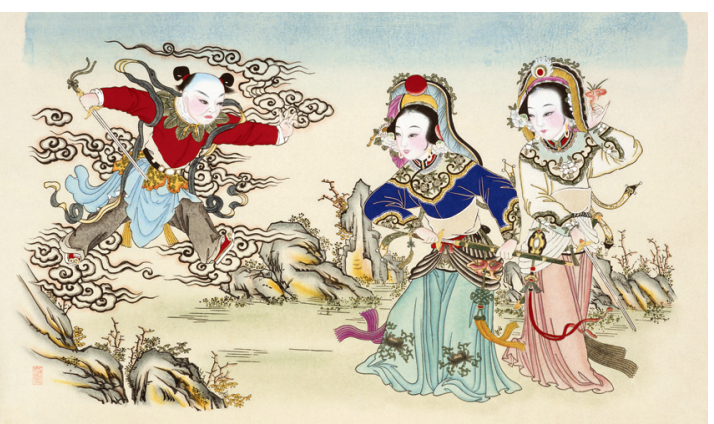

1. Stealing Celestial Grass,

$67 \mathrm{~cm} \times 112.5 \mathrm{~cm}$, Late Qing Dynasty.

Collection of the National Art

Museum of China.

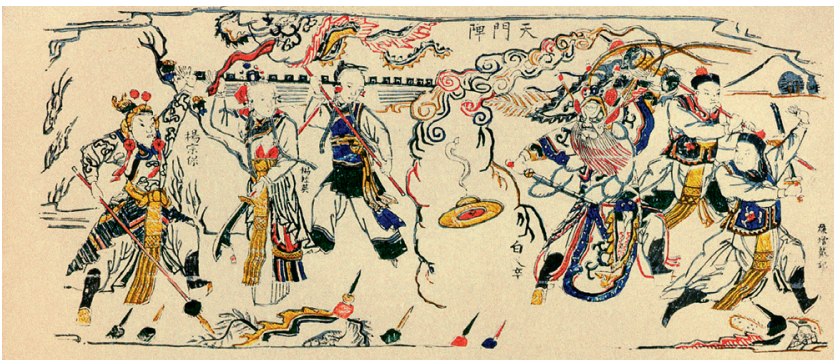

2. Dai Lianzeng Workshop:

The Yang Warrior Family,

$100 \mathrm{~cm} \times 63 \mathrm{~cm}$, early Qing

Dynasty. Collection of the

National Art Museum of China.
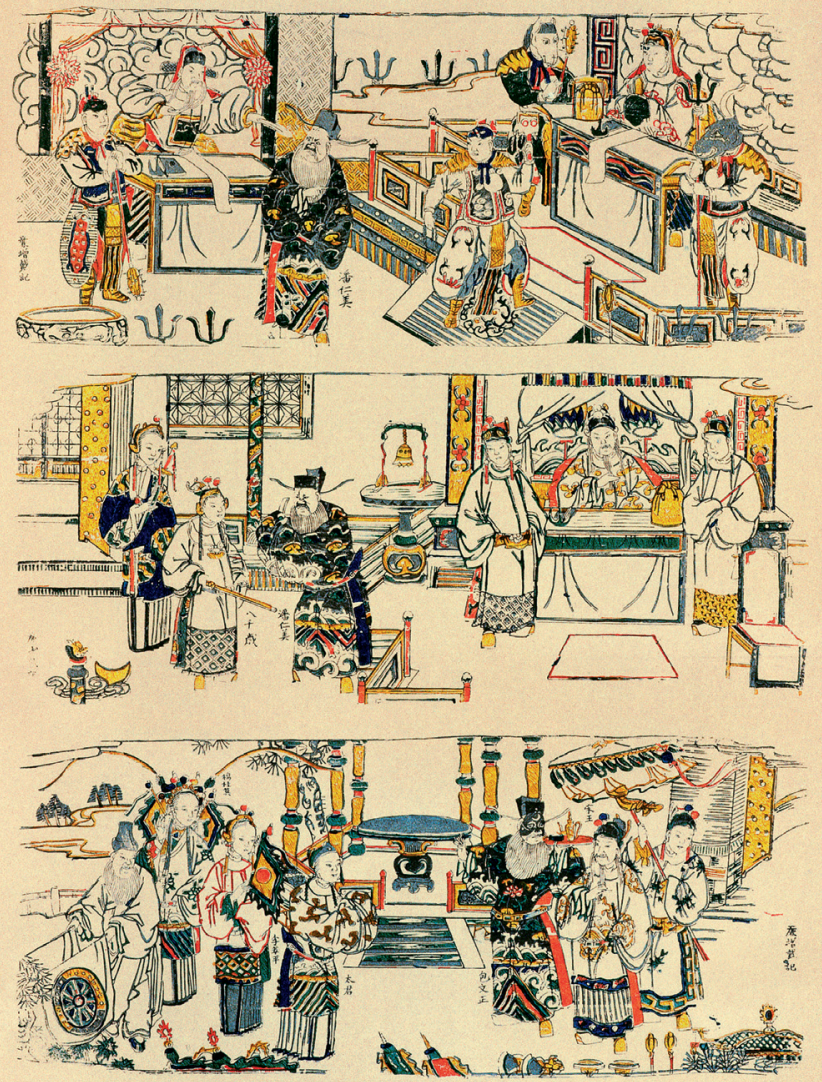


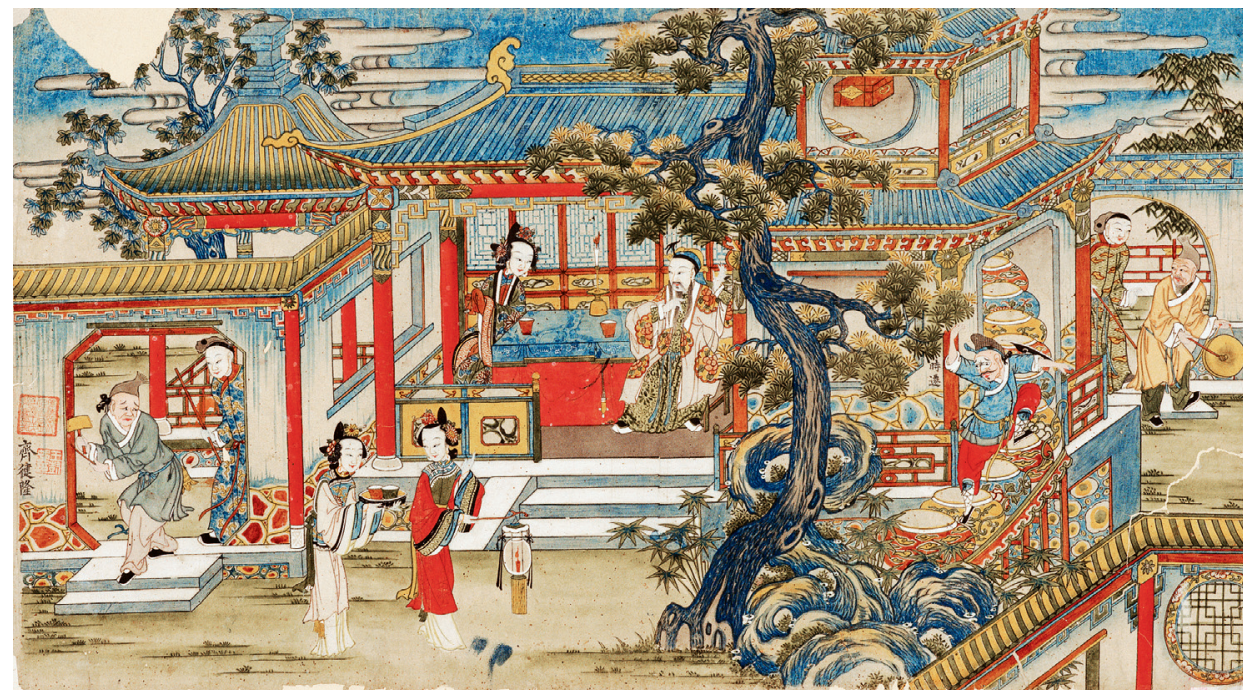

3. Shi Qian Stole the Armor, $60 \mathrm{~cm} \times 109.5 \mathrm{~cm}$, Jiaqing Period - Qing Dynasty. Collection of the National Art Museum of China.

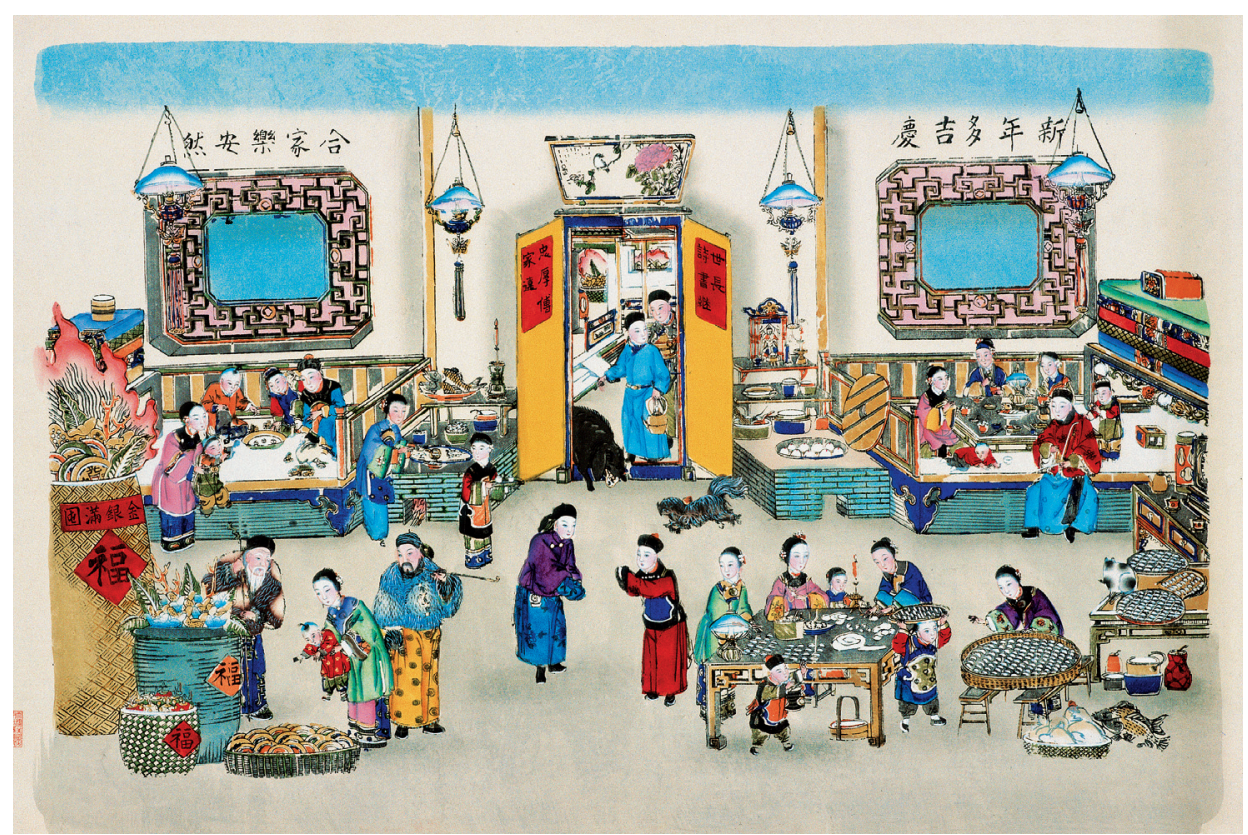

4. A Prosperous and Peaceful New Year, $59 \mathrm{~cm} \times 102 \mathrm{~cm}$, late Qing Dynasty. Collection of the National Art Museum of China. 


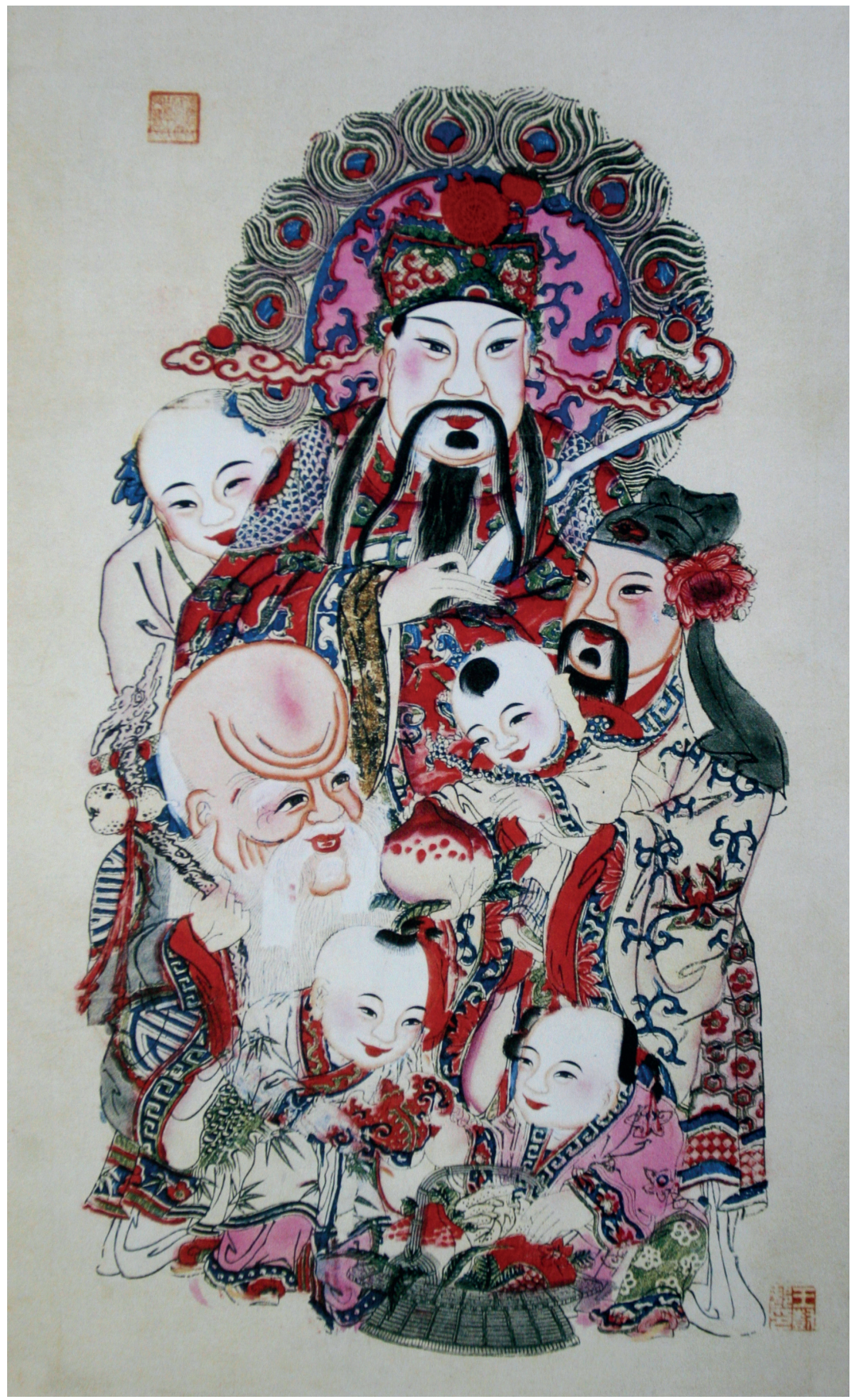

5. Gods of Fortune, Prosperity and Longevity, $110 \mathrm{~cm} \times 61 \mathrm{~cm}$, late Qing Dynasty. Collection of the National Art Museum of China. 

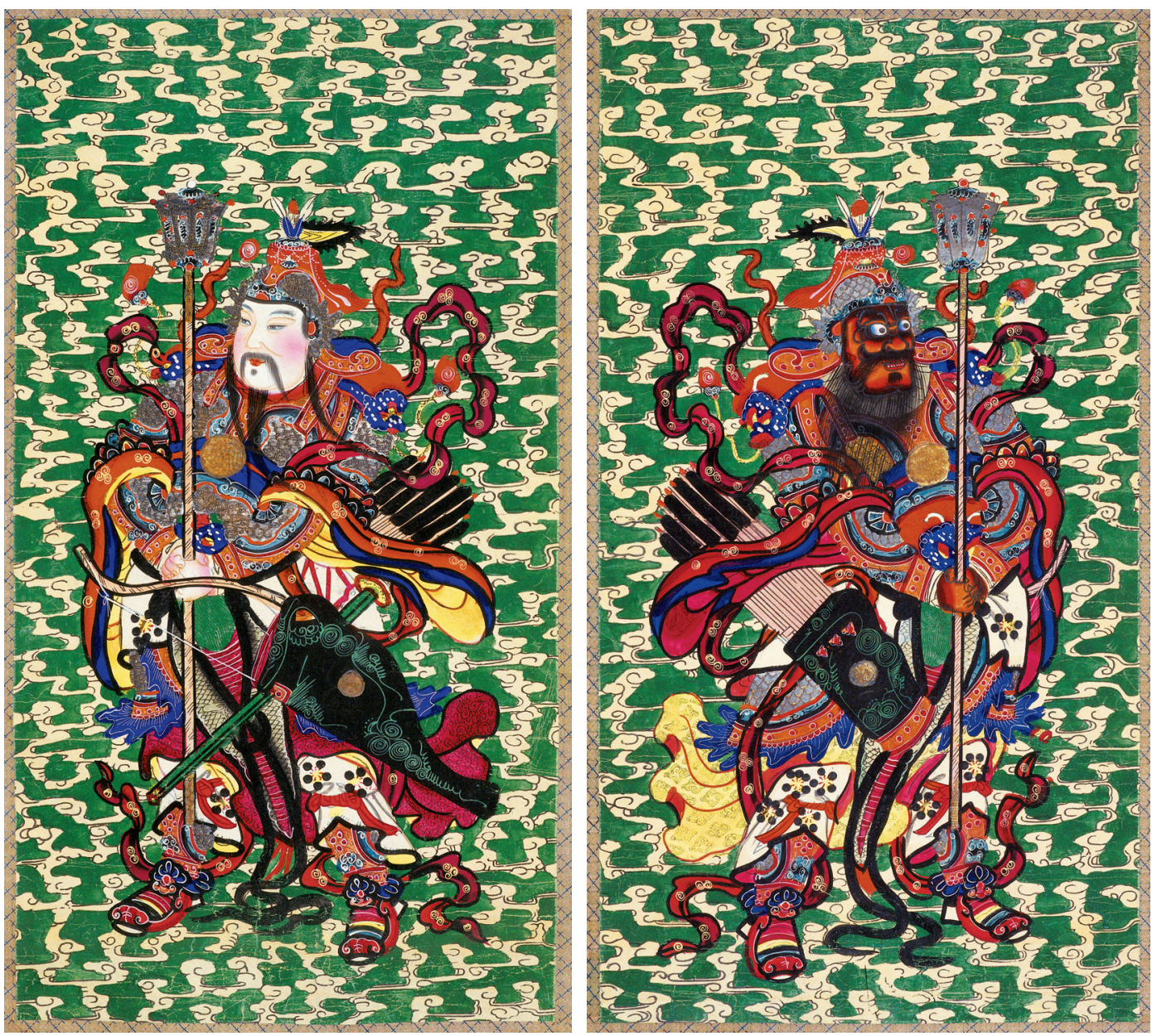

6. Door Gods: Qin Qiong and fing De, $120 \mathrm{~cm} \times 64 \mathrm{~cm}$, late Qing Dynasty. Collection of the National Art Museum of China. 


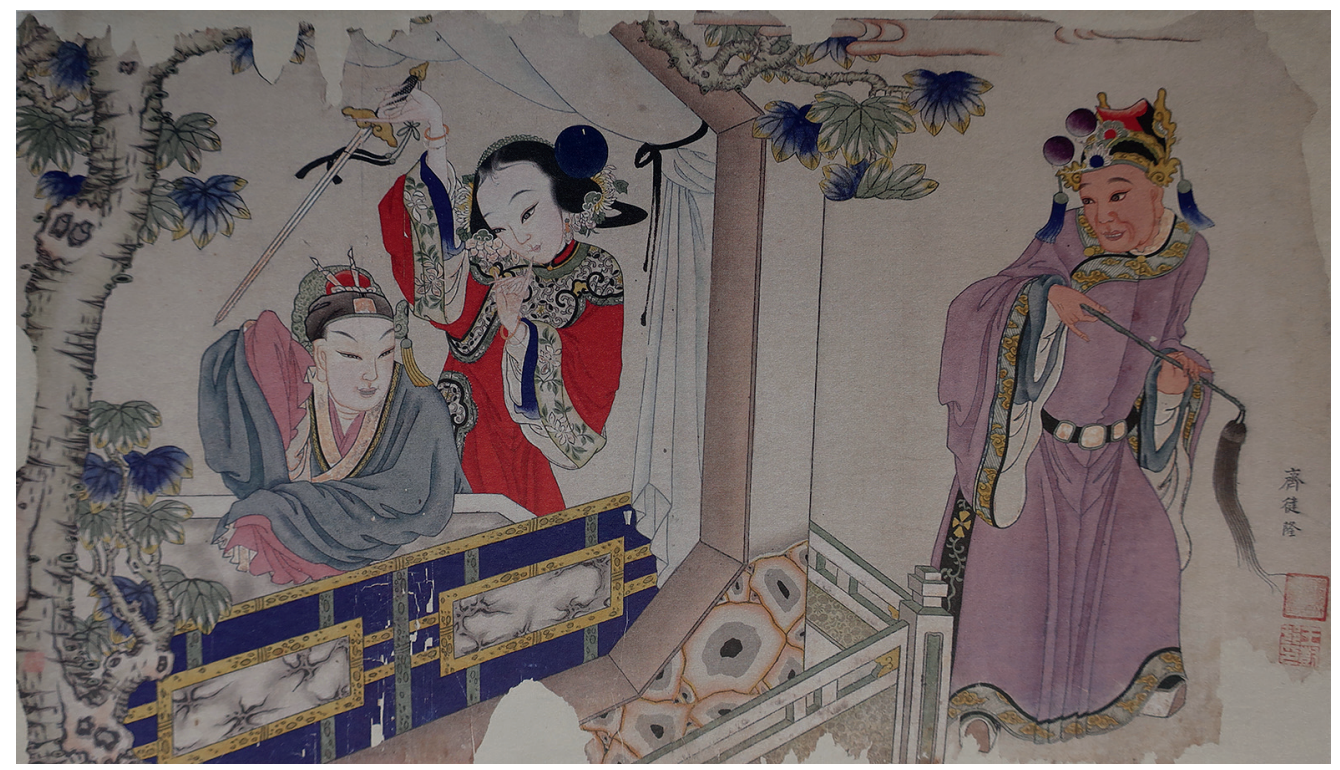

7. Princess Flowers, $59.5 \mathrm{~cm} \times 105.5 \mathrm{~cm}$, Qianlong Period - Qing Dynasty. Collection of the National Art Museum of China.

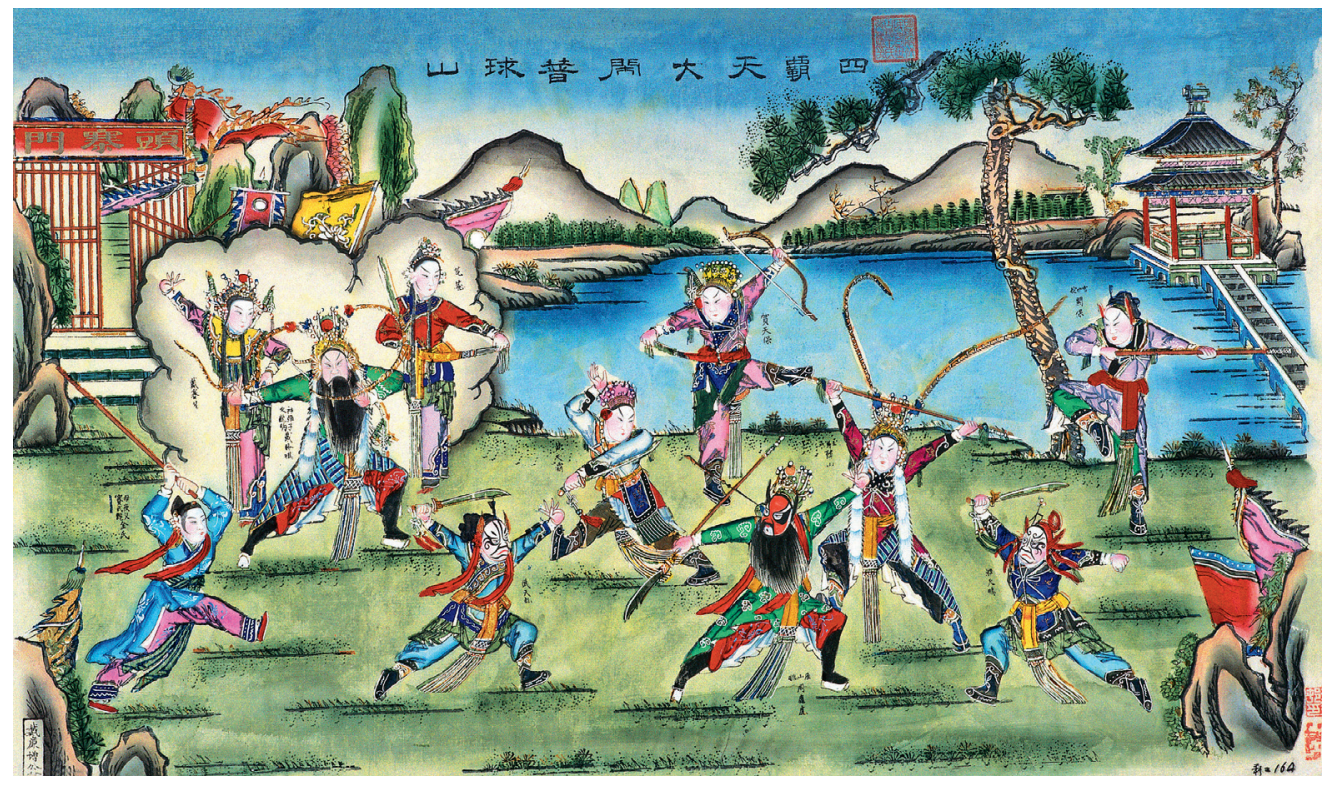

8. Four Local Tyrants Raise a Rumpus in the Puqiu Mountain, $57 \mathrm{~cm} \times 100 \mathrm{~cm}$, Qing Dynasty. Collection of the National Art Museum of China. 


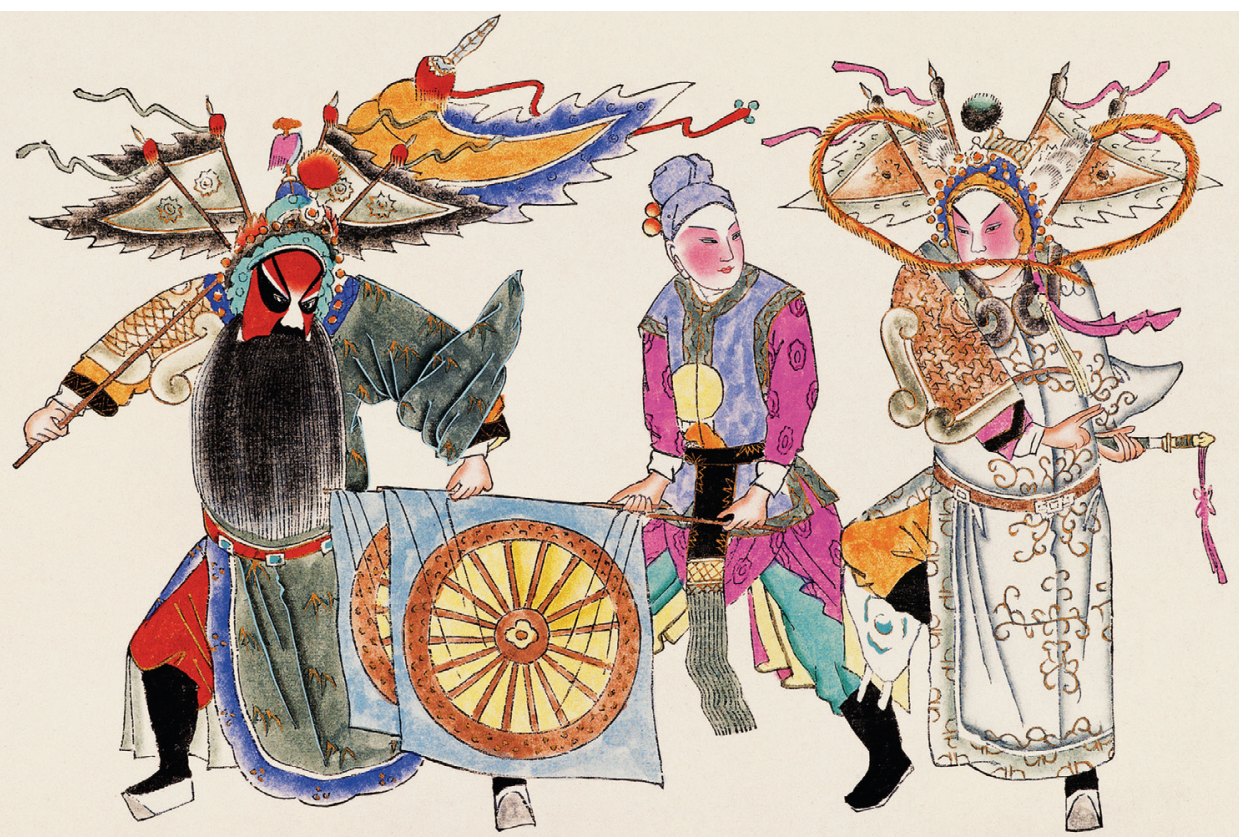

9. Sending armed forces to suppress Zidu, $23 \mathrm{~cm} \times 30 \mathrm{~cm}$, late Qing Dynasty. Collection of the National Art Museum of China.

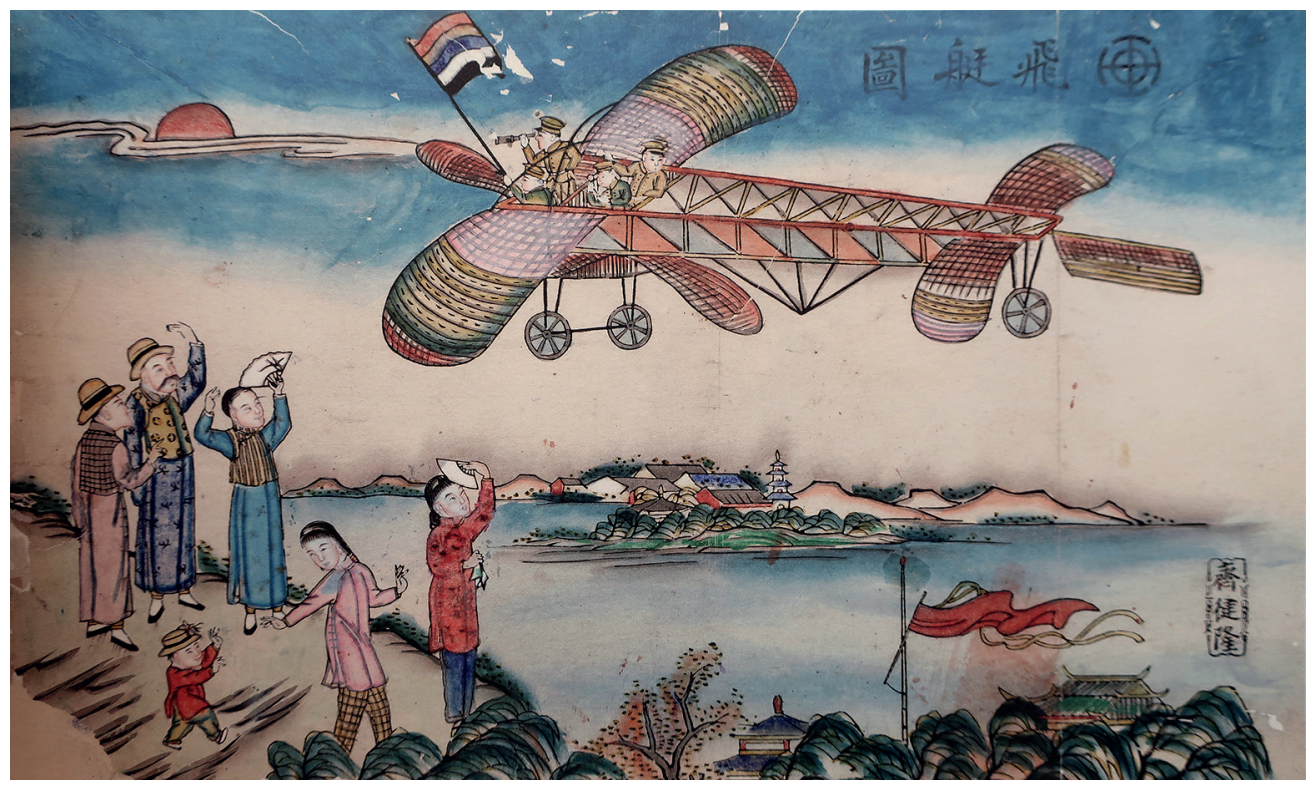

10. Airship, $33 \mathrm{~cm} \times 59 \mathrm{~cm}$, First Year Period of Republic of China. Collection of the National Art Museum of China. 


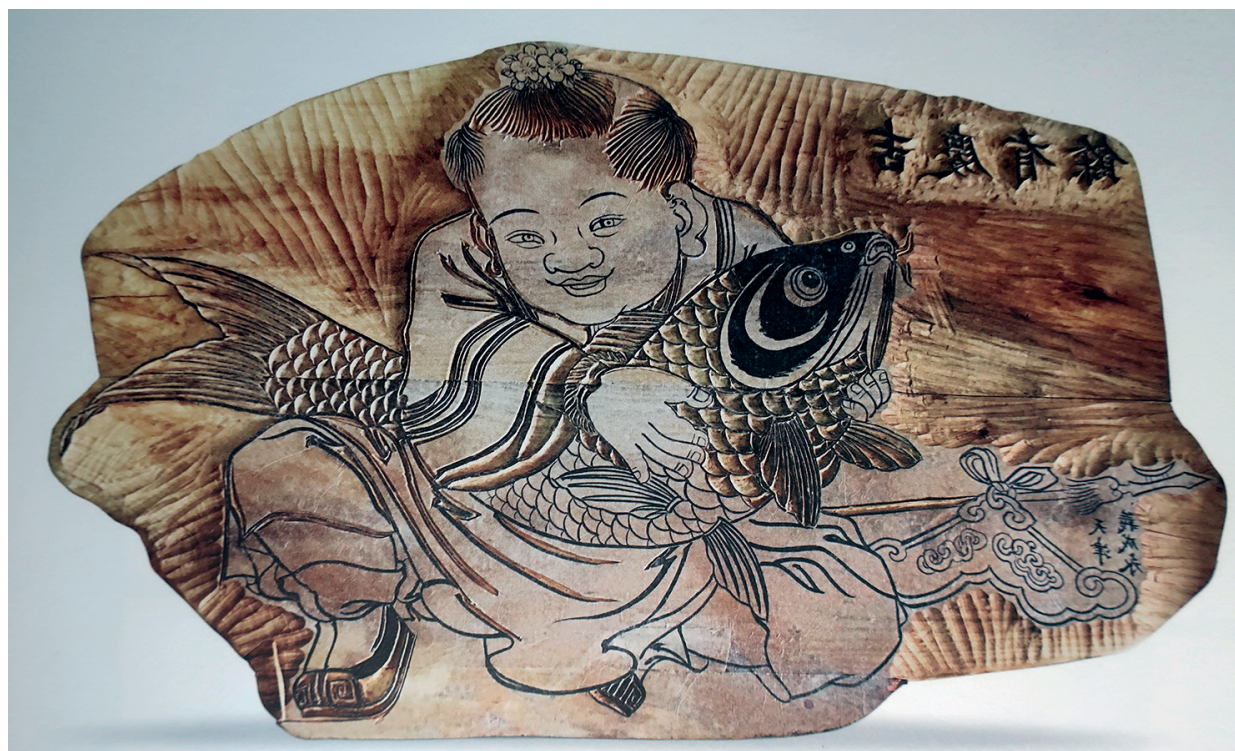

11. Wood block. Collection of the National Art Museum of China.

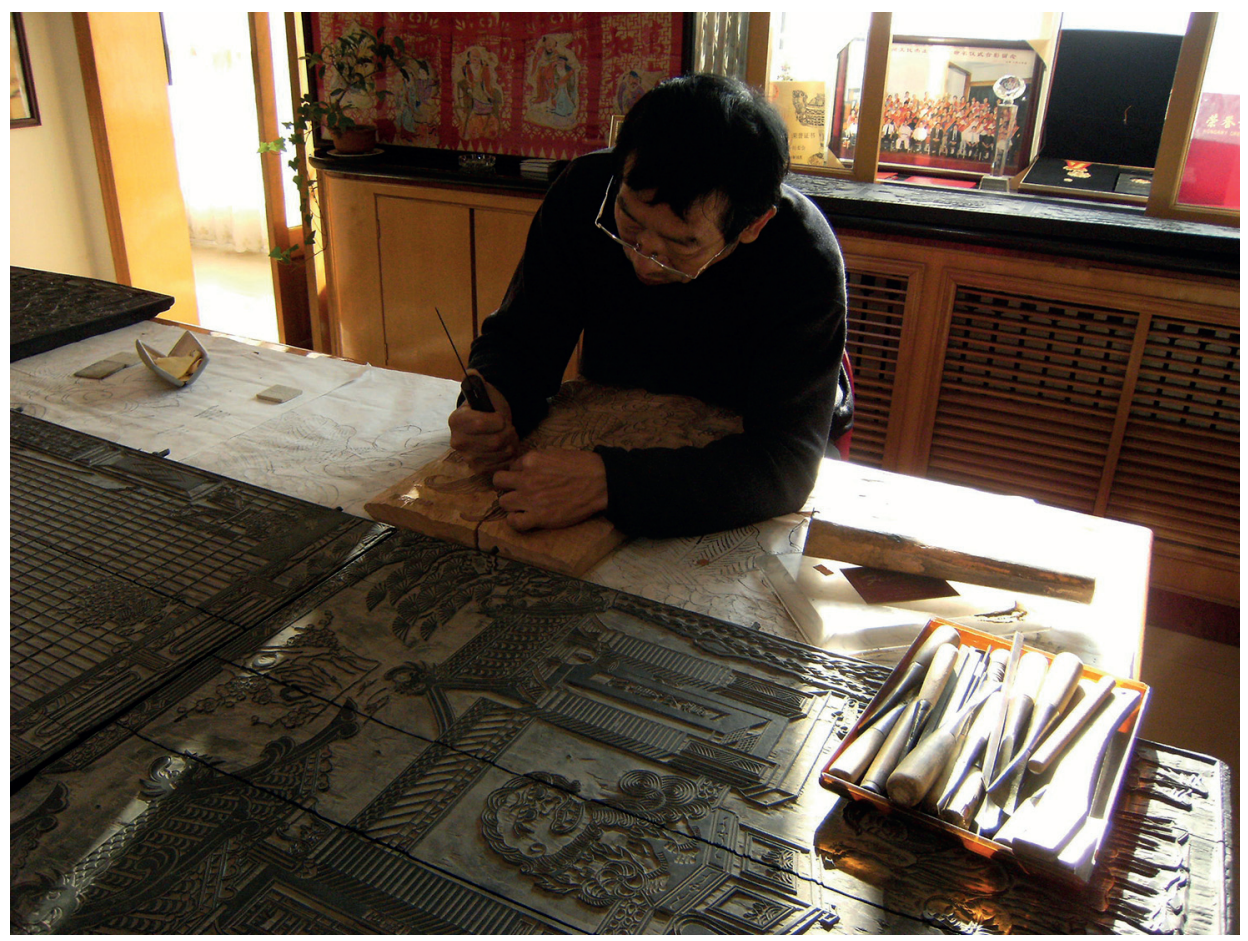

12. Engraving. Collection of the National Art Museum of China. 


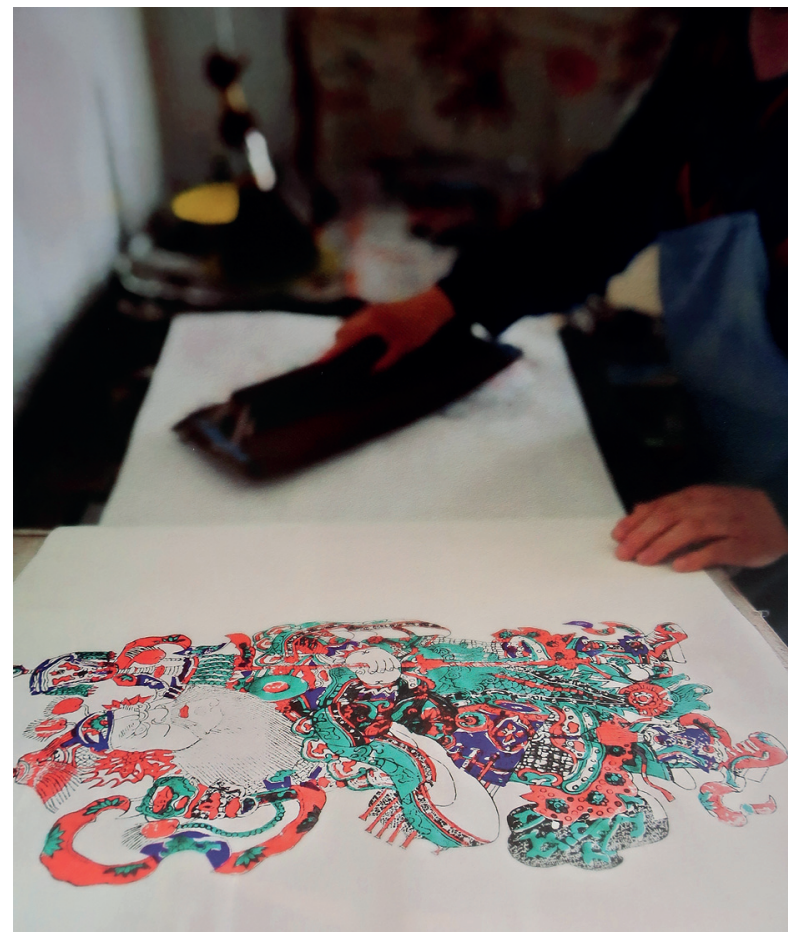

13. Printing. Collection of the National Art Museum of China.

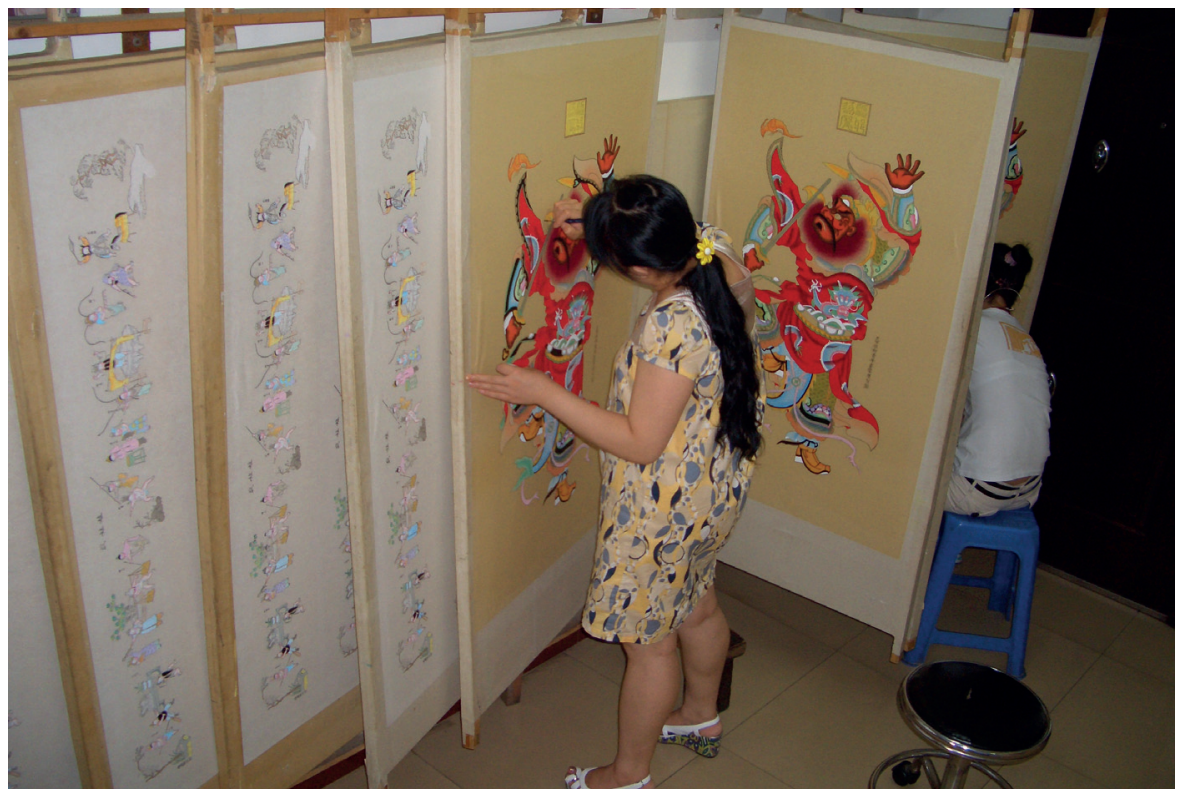

14. Painting. Collection of the National Art Museum of China. 


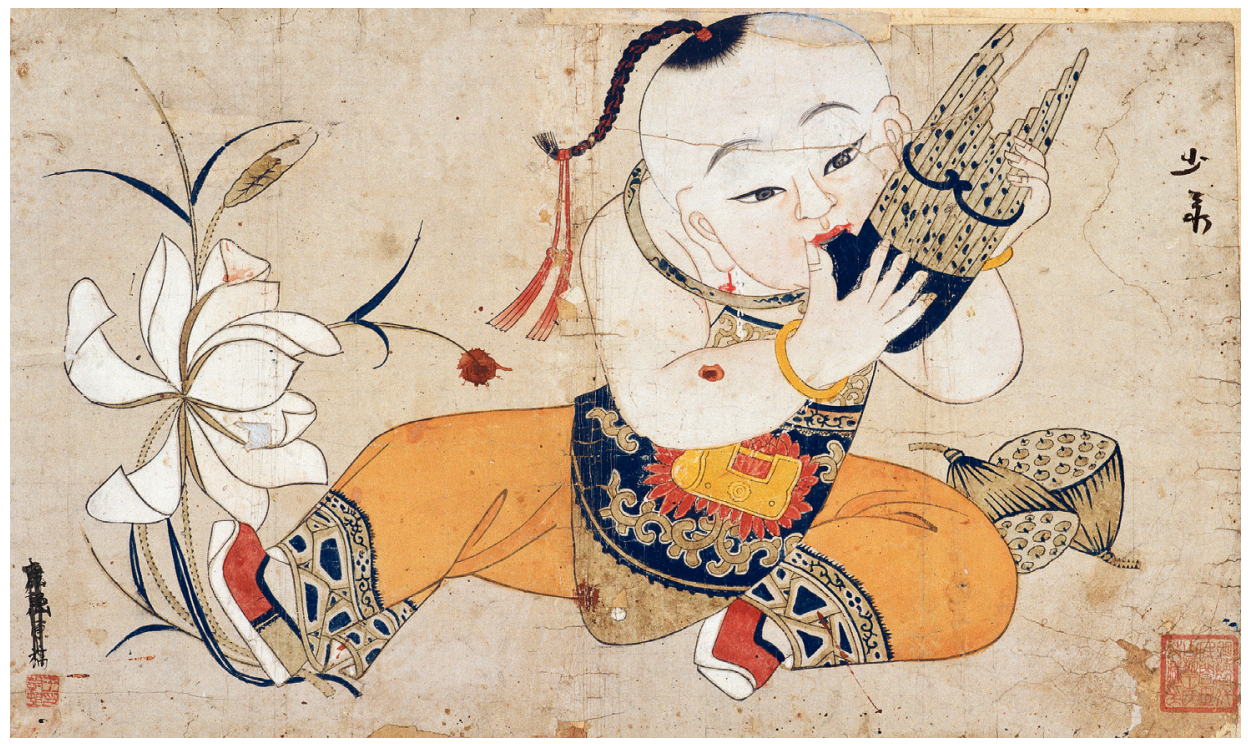

15. Honourable Offspring after Another, $30.5 \mathrm{~cm} \times 50 \mathrm{~cm}$, Kangxi Period - Qing Dynasty. Collection of the National Art Museum of China.

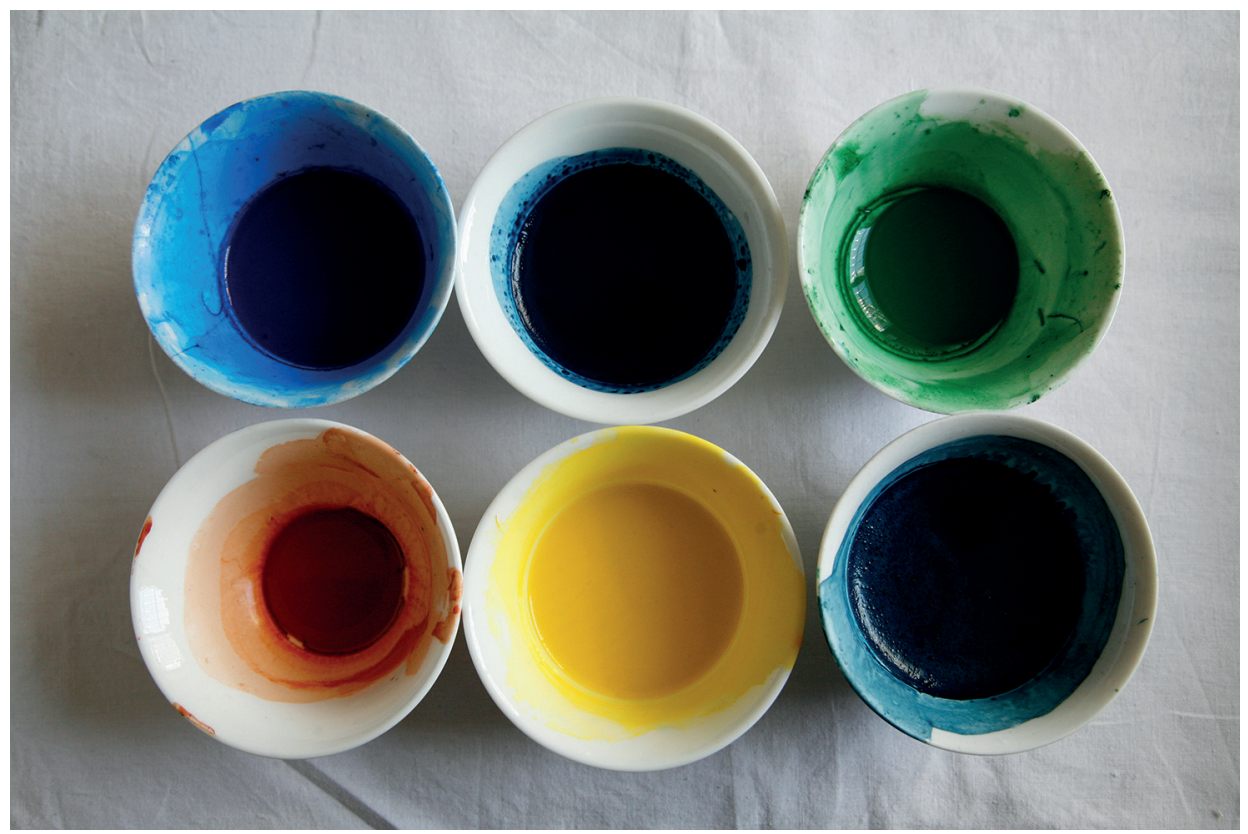

16. Traditional Chinese Painting Pigments. Collection of the National Art Museum of China. 


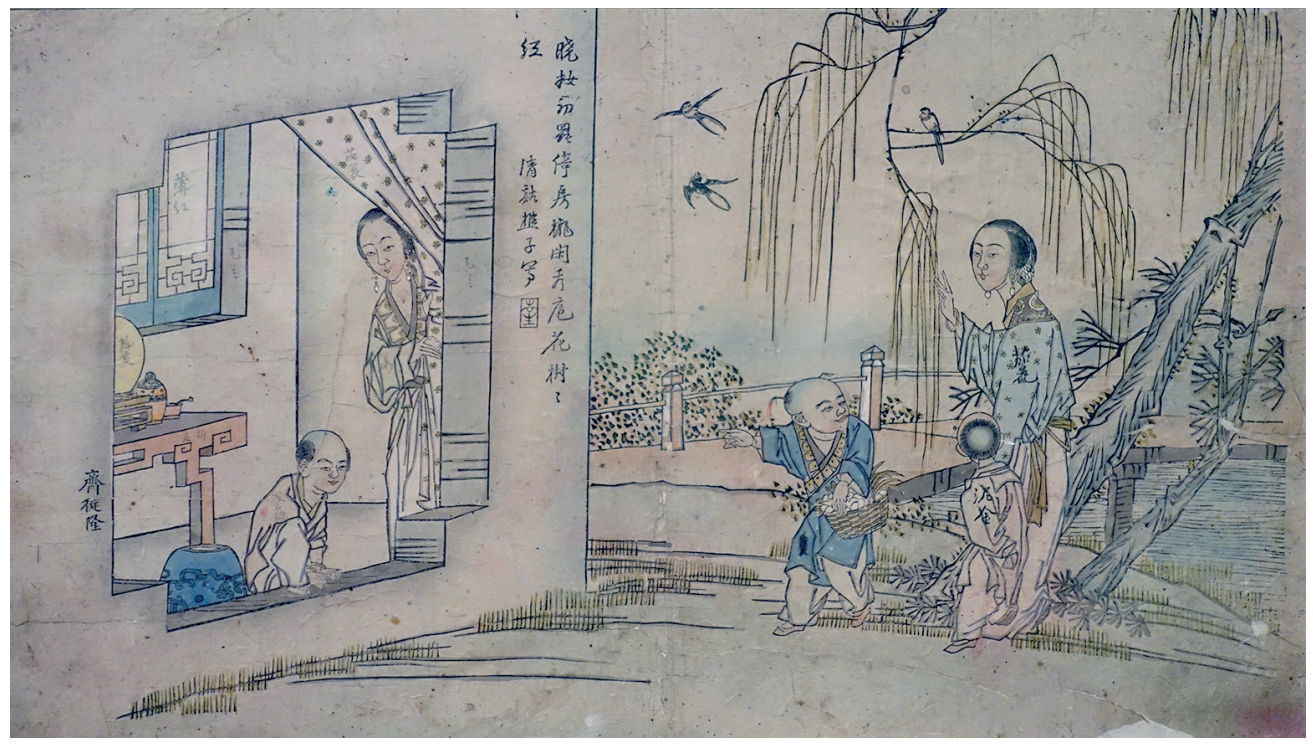

17. Qian Hui'an: Admiring Flowers of a Garden, $33 \mathrm{~cm} \times 67 \mathrm{~cm}$, Guangxu Period - Qing Dynasty. Collection of the National Art Museum of China.

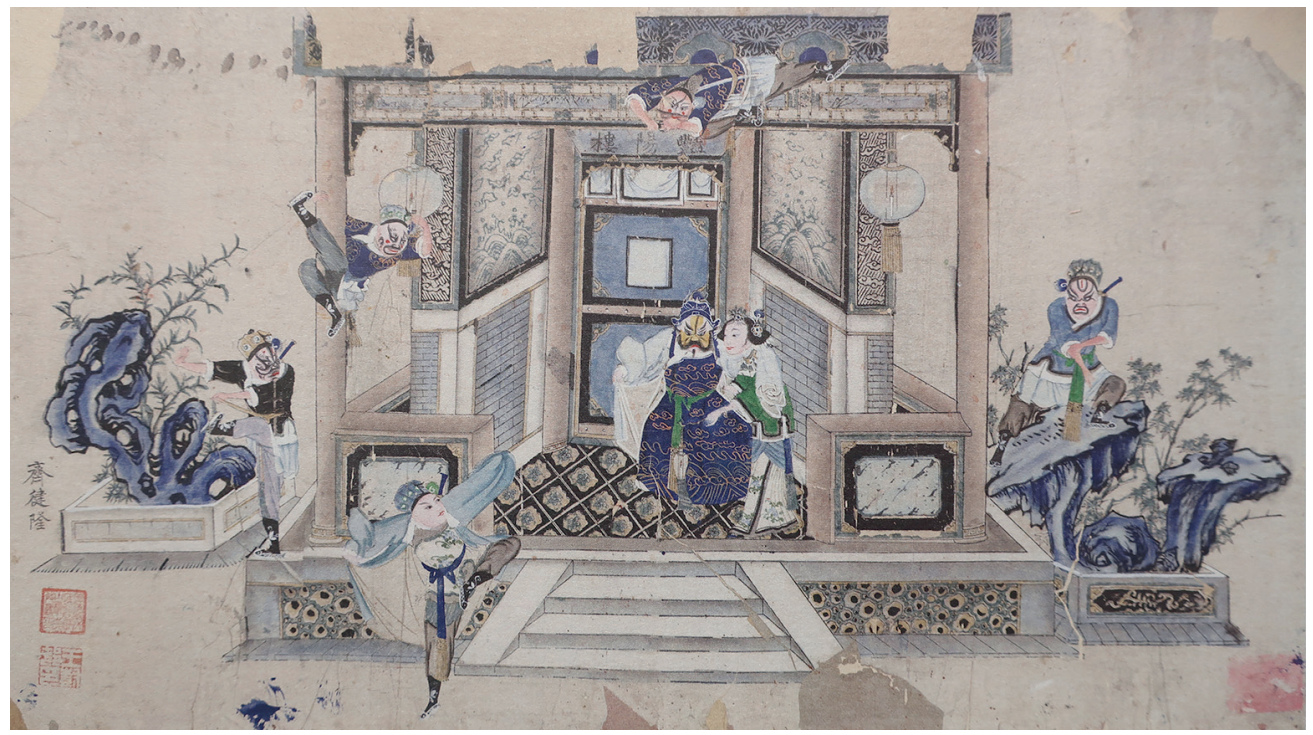

18. Pavilion of the Sun, $58 \mathrm{~cm} \times 103 \mathrm{~cm}$, Tongzhi Period - Qing Dynasty. Collection of the National Art Museum of China. 